\title{
Is resolution the end of inflammation?
}

\author{
Karen T. Feehan and Derek W. Gilroy*
}

Centre for Clinical Pharmacology and Therapeutics, Division of Medicine, 5 University

Street, University College London, London WC1E 6JF, United Kingdom

*Corresponding author: Derek W. Gilroy d.gilroy@ucl.ac.uk

Keywords: Resolution, post-resolution, adapted homeostasis, chronic inflammation, autoimmunuty

\begin{abstract}
Deciphering the origins of chronic inflammatory and autoimmune diseases remains elusive with reliance on therapies aimed at halting inflammation in its tracks. In recent years, an appreciation of targeting pathways by which inflammation is resolved are beginning to pique interest. Resolution of inflammation is driven by a complex set of mediators that regulate cellular events required to clear inflammatory cells from sites of infection or injury to restore tissue function. However, recent studies suggest that resolution is not the end of innate mediated immune responses to infection/injury. There is further immunological activity occurring after the resolution cascade is complete that alters the immune physiology of tissues, redefining what was once termed restorative homeostasis as 'adapted homeostasis'.
\end{abstract}




\section{Acute and chronic inflammation}

Activation of an acute inflammatory response is a fundamental requirement to eradicate threats to the host organism such as bacterial or viral infections. Initiation of inflammation, the manifestation of infection or injury, is mediated by resident immune cells via pathogen recognition receptors (PRRs) such as toll-like receptors (TLRs) [1], leading to the synthesis of soluble mediators such as pro-inflammatory cytokines which activate downstream proinflammatory signalling pathways [2]. Concomitantly, upregulation of cell adhesion molecules on circulating leukocytes and endothelial cells promotes the influx of granulocytes and mononuclear phagocytes from the blood. Upon arrival, granulocytes such as neutrophils primarily function to phagocytose and eliminate tissue debris and microorganisms through distinct intracellular mechanisms such as the production of reactive oxygen species (ROS) including hydrogen peroxide, superoxide anion and hydroxyl radical, and/or extracellular mechanisms via the release of neutrophil extracellular traps (NETS) [3].

Uncontrolled inflammation is a key player in the pathogenesis of a myriad of chronic diseases including rheumatoid arthritis (RA) [4], systemic lupus erythematosus (SLE) [5] and chronic granulomatous disease (CGD), a primary immunodeficiency affecting phagocytes leading to greatly increased susceptibility to severe bacterial and fungal infections [6, 7]. Over the past 50 years, research has focused on understanding the mediators that cause chronic inflammatory responses in order to treat these diseases, predominantly aiming to inhibit the synthesis or action of mediators that drive inflammation using drugs including non-steroidal antiinflammatory drugs (NSAIDs) and anti-cytokine therapies such as anti-tumour necrosis factor $\alpha($ anti-TNF $\alpha)$. However, recent years have seen an increased interest on the other end of the inflammatory spectrum - the resolution process, a critical requirement for the inflammatory response to switch off - aiming to develop drugs which drive pro-resolution pathways. 
Importantly, recent studies of immune responses during acute inflammation suggest that resolution is not the end of innate mediated immune responses to infection or injury, but that there is further immunological activity occurring after the resolution cascade is complete that alters the immune physiology of tissues post injury. This review discusses resolution processes and recent developments surrounding this emerging concept of post-resolution immune activity and its implication in the development of chronic inflammatory and autoimmune conditions.

\section{Resolution of acute inflammation}

Resolution is the process responsible for switching inflammation off and was traditionally characterised as a passive process [8, 9]. However, recent years have produced numerous studies stating that resolution is, in fact, an active process, characterised by a sequence of events coordinated by a complex set of mediators (table 1) that regulate cellular events required to clear inflammatory cell from sites of infection or injury to restore tissue function [10].

\section{Elimination of inciting stimulus}

For effective resolution of acute inflammation, the inciting stimulus must be eliminated, for example in the case of bacterial infection the removal of the pathogen facilitates the initiation of resolution. Failure to do so leads to the development of chronic inflammation as is demonstrated in chronic granulomatous disease (CGD). CGD is characterised by a failure of the phagocytic NADPH oxidase to generate reactive oxygen species [7]. This results in failure to kill a specific spectrum of bacteria, particularly those that are catalase-positive such as Staphylococcus aureus (S. aureus), Klebsiella species, Listeria species and Escherichia coli (E. coli), and also fungi such as the Aspergillus and Candida species [11]. This leads to the development of hyperinflammation and widespread formation of granulomas, compact collections of inflammatory cells, predominantly mononuclear phagocytes such as 
macrophages. [6, 7]. Similarly, in Mycobacterium tuberculosis infection, failure to clear the bacteria from the lung tissue results in persistence for decades and the development of chronic mycobacterium driven granulomatous disease [12, 13].

\section{Dampening pro-inflammatory signals}

It is reasonable to expect that the signalling pathways that trigger the release of proinflammatory mediators must be turned off in order to prevent the development of overexuberant inflammation [14]. For example, TLR signalling leading to the activation of the transcription factor nuclear factor kappa-light-chain-enhancer of activated B cells (NF- $\kappa \mathrm{B})$, for example, results in the production of TNF $\alpha$ [15], a cytokine that is routinely targeted in therapies for patients with chronic inflammatory conditions such as rheumatoid arthritis (RA) [16]. TLRs consist of three domains which are vital for their function. These include (1) an extracellular ectodomain containing leucine rich repeats (LRRs), this domain facilitates the detection of conserved structures of pathogens called pathogen-associated molecular patterns (PAMPs), (2) a transmembrane segment, and (3) an intracellular Toll-interleukin (IL)-1 receptor (TIR) domain, which interacts with downstream adaptors or signalling proteins [17]. Leucine Rich Repeat Containing 33 (LRRC33) is a TLR homolog that lacks a TIR domain, but instead contains a short cytoplasmic tail of 21 amino acids. LRRC33 contains an extracellular domain with 17 LRRs, which directly interacts with TLRs in order to restrain inflammatory responses. LRRC33-TLR interactions inhibit NF- $\mathrm{kB}$ activation and cytokine production mediated by various TLR ligands including peptidoglycan (PGN) for TLR2, lipopolysaccharide (LPS) for TLR4 and bacterial DNA for TLR9 [18]. Thus, several regulatory mechanisms exist to facilitate the dampening of pro-inflammatory signalling. 


\section{Pro-inflammatory mediator catabolism}

Once pro-inflammatory signalling pathways are dampened, the next phase of resolution involving pro-inflammatory mediator catabolism takes place. It is important that levels of cytokines, chemokines, eicosanoids, cell adhesion molecules, etc. are regulated to avoid chronic inflammatory responses. Prostaglandins (PGs) for instance are catabolised via the oxidation of the 15(S)-hydroxyl group by a 15-hyroxyPG dehydrogenase, which metabolises E-series PGs, lipoxins (Lxs), 15-HETE, 5, 15-diHETE and 8, 15-diHETE to the corresponding 15-keto compound [19]. The second step involves the reduction of the $\Delta 13$ double bond by an NADPH/NADH dependent $\Delta 13-15$ ketoPG reductase. Some PGs are further catabolised via the beta-oxidation pathway i.e via the carboxyl end of the molecule, leading to the formation of short chain metabolites, which are excreted in the urine.

Another family of mediators requiring negative regulation during resolution are chemokines

(Table 2). Chemokines are produced in abundance during onset of inflammation and initiate leukocyte migration to the affected tissue [20]. To attain a resolving environment, chemokine cleavage and sequestration are necessary to stop further neutrophil influx. Neutrophils are mobilised to the site of inflammation during onset via a chemotactic gradient, where they generate an abundance of proteases and reactive oxygen species (ROS) which allow for rapid killing of phagocytosed pathogens $[21,22]$. These toxic molecules can also damage host tissue following their release, thus it is important that neutrophils are cleared from the tissue in order to prevent further damage [23]. Matrix metalloproteinase (MMP)- dependent chemokine cleavage results in the cleavage of CXC family chemokines. The CXC or Alpha chemokines are characterised by the separation of the first two cysteine residues in the amino acid sequence by one amino acid (C-X-C). This family primarily acts on neutrophils as chemoattractants, for example CXCL8, or IL-8, is a major chemoattractant for neutrophils during the onset of inflammation. MMPs cleave CXC chemokines at an ELR motif, which is crucial for interaction 
with G protein-linked transmembrane receptors (GPCRs) called chemokine receptors, that are found selectively on the surfaces of target cells, for instance, CXCR1 expression on the surface of neutrophils [24, 25]. Without an active receptor binding site, the chemokine can no longer recruit neutrophils, thus, preventing further neutrophil chemotaxis.

Dampening of leukocyte recruitment at inflammatory sites can also be mediated a group of recently discovered chemokine receptors termed "silent" or "decoy" receptors. This groups includes D6, DARC and CCX-CKR, which are defined as non-signalling receptors that prevent cell chemoattraction through competition with other signalling receptors for chemokines. The D6 chemokine decoy receptor is expressed on the lymphatic endothelium and is structurally similar to CCR4 and CCR5 [26, 27]. Here, it competes and binds to members of the inflammatory CC or beta chemokine family (CCL2, CCL3, CCL4, CCL5 etc.) [28]. Beta chemokines are characterised by two adjacent cysteines $(\mathrm{C}-\mathrm{C})$ and predominantly chemoattract monocyte and macrophage populations to sites of inflammation. Once bound, D6 actively internalises the entire ligand-receptor complex through clathrin-coated pits where the chemokine is then targeting for degradation. D6 is then recycled back to the cell membrane.

Thus, endogenous systems exist to facilitate pro-inflammatory signalling cessation leading to pro-inflammatory mediator clearance. Such mechanisms terminate neutrophil infiltration thereby preventing further pro-inflammatory processes driven by persistent neutrophilia.

\section{Efferocytosis}

Effective resolution not only requires cessation of neutrophil recruitment but also removal of emigrated neutrophils from the site of inflammation to limit their potentially harmful actions [30]. Apoptosis represents a highly organised form of programmed cell death which results in 
extensive blebbing of the plasma membrane followed by destructive fragmentation of the nucleus and separation of cell fragments into apoptotic bodies during a process called "budding". The integrity of the apoptotic body is maintained with all organelles enclosed within an intact plasma membrane thereby preventing the release of cytotoxic agents into the surrounding environment [31]. For appropriate clearance, apoptotic cells must be taken up by phagocytes in a process known as efferocytosis [32]. The specific recognition of an apoptotic cell or apoptotic bodies depends on changes in the expression of cell surface molecules [33]. During apoptosis, the dying cell upregulates expression of various 'eat-me' signals. 'Eat-me' signals are exposed or released by apoptotic cells to trigger phagocytic uptake, such 'eat-me' signals include phospholipids, nucleotides and phosphatidylserine (PtdSer) [34]. Cell surface expression of PtdSer is the most universally documented alteration on the surface of apoptotic cells. PtdSer is normally confined to the inner leaflet of viable cells via flippases which establish asymmetrical phospholipid localisation by transporting PtdSer from the outer to the inner leaflet of the lipid bilayer. However, during apoptosis PtdSer is enriched on the exofacial side of the membrane of apoptotic bodies due to the activation of caspases, for instance the intrinsically, cytochrome c/Apaf-1, activated caspase 9, leading to the activation of the effector caspases 3 and 7. These effector caspases simultaneously cleave and inactivate the flippase ATP11C, and activate the scramblase xkr8. Activation of scramblases such as xkr8 allows for the bidirectional transport of phospholipids in the plasma membrane resulting in surface expression of PtdSer [35]. Multiple distinct receptors on the surface of macrophages can bind to PtdSer [36], such as members of the $\mathrm{T}$ cell/transmembrane, immunoglobulin, and mucin (TIM) family [37, 38]. The TIM family consists of eight members (TIM 1-8) [39], from which TIM-1, TIM-3 and TIM-4 have been demonstrated to be specialised for the recognition of PtdSer but differ in expression [38]. TIM-4 is exclusively expressed on antigen-presenting cells and plays a key role in mediating phagocytosis of apoptotic cells [38]. Once bound to TIM-4, 
PtdSer is tethered to the surface of the phagocyte. Tethering allows for the binding of soluble proteins such as protein S/Gas6 or FG-E8 which activate their receptors; MerTK or integrin respectively, resulting in Rac1 activation and actin polymerization. Collectively, these signals result in apoptotic cell engulfment by phagocytes such as macrophages.

The uptake of apoptotic neutrophils triggers the conversion of the pro-inflammatory phagocytosing macrophage to an anti-inflammatory, immune regulatory or pro-resolution phenotype [40]. This 'polarisation' is important to maintain tolerance both locally and in the draining lymphoid organs to limit potential collateral tissue damage [41]. This pro-resolution phenotype is characterised by the upregulation of co-inhibitory molecules such as PDL1 and ICOS ligand along with the upregulation of an anti-inflammatory gene transcription programme resulting in the release of anti-inflammatory cytokines such as IL-10 and TGF $\beta$, the secretion of PCNA-associated factor, $\mathrm{PGE}_{2}$ and cAMP [40, 42]. Macrophages that have ingested apoptotic cells also release specialised pro-resolving lipid mediators (table 1) such as RvE1, protectin D1 and maresin, contributing to termination of the inflammatory process [43, 44] Thus, efferocytosis is not only required for elimination of apoptotic neutrophils but also for generating an anti-inflammatory macrophage phenotype conducive to resolution.

Failure of efferocytosis has been proposed to be involved in SLE, in which individuals develop autoantibodies due to a failure to clear apoptotic bodies. It is hypothesised that defects in apoptotic cell clearance could lead to the accumulation of apoptotic bodies which harbour the immunogens responsible for antinuclear antibody formation [5, 45]. Defective efferocytosis has also been implicated in the development of many other chronic inflammatory and autoimmune diseases including chronic obstructive pulmonary disease (COPD) [46], asthma [47], RA [48], atherosclerosis [49] and glomerulonephritis [50]. 
Impaired resolution pathways are implicated in the development of a myriad of inflammatory and autoimmune diseases, thus it is clear that inflammatory resolution may be a key target for the development of therapeutics.

\section{Specialised pro-resolving mediators (SPMs)}

Many effective anti-inflammatory treatments are readily available on the market, including NSAIDs, anti-cytokine therapies and steroids. However, switching off the underlying disease process is much more challenging. With increased focus on elucidating inflammatory resolution pathways, it now stands that diseases driven by ongoing inflammation could be treated by activating or enhancing these pathways rather than simply stopping inflammation in its tracks.

Specialised pro-resolving mediators (SPMs), represent a subset of lipids that have a powerful effect on reducing inflammation via enhancement of pro-resolution pathways (table 1). Resolving inflammatory exudates use omega-3 fatty acids to produce structurally distinct families of signalling molecules - resolvins, protectins and maresins. SPMs exert their proresolving functions as molecular signals via specific receptors. For example, the GPCR leukotriene B4 receptor 1 (BLT1) which is expressed primarily on leukocytes [51], is a high affinity receptor for leukotriene $\mathrm{B} 4\left(\mathrm{LTB}_{4},\right)$ during inflammation. $\mathrm{LTB}_{4}$ is a product of arachidonic acid (AA) metabolism, synthesised by the sequential actions of 5-lipoxygenase (5LO) and leukotriene A4 hydrolase $\left(\mathrm{LTA}_{4} \mathrm{H}\right)$ [52]. $\mathrm{LTB}_{4}$ is a potent chemoattractant for neutrophils and a key player in the initiation of inflammation [53]. However, during resolution BLT1 directly interacts with the eicosapentaenoic acid (E-series) derived resolvin E1 (RvE1), a key lipid in the SPM family. This leads to attenuation of pro-inflammatory signals by $\mathrm{LTB}_{4}$, inhibiting neutrophil infiltration and degranulation in the affected tissue [54]. Additionally, SPMs also play a role in enhancing efferocytosis during the resolution of acute inflammation. 
Resolvin D1 (RvD1) signalling through GPR32 or AXL/FPR2 in human monocytes, for example, stimulates a phagocytic response, enhancing macrophage efferocytosis of apoptotic cells [55].

Hastening resolution via pro-resolving pathways has traditionally been thought to lead to incomplete clearance of the original trigger, particularly in the context of ongoing infections [56]. However, SPMs have also been shown to enhance cellular anti-microbial function in addition to their pro-resolving functions. For example, the chemokine-like receptor (ChemR23)-RvE1 axis stimulates macrophage phagocytosis of invading pathogens via phosphoinositide 3-kinase (PI3K)/Akt and Raf/extracellular signal-regulated kinase (ERK) pathways phosphorylation of ribosomal protein S6, a downstream target $[54,57,58]$. Clinically the mainstay for treatment of acute bacterial infections involves the use antibiotics, in light of the ever-growing threat of antibiotic resistance SPM enhancement of cellular antimicrobial function represent a potential target for the development of new anti-infective therapeutics.

The identification of SPMs as novel bioactive products and their role in regulating both early (neutrophil recruitment) and late responses (macrophage efferocytosis) represents a key target for the development of pharmacological resolution - directed interventions which aim to activate and accelerate endogenous resolution processes. Utilising such interventions, and with their exhibited anti-microbial functions, SPMs represent an exciting strategy, providing new ways to control inflammation and its potentially harmful side effects, mainly tissue damage and injury.

\section{New insights into immune activity after resolution}


Resolution is typically defined as a tightly regulated process that restores tissue homeostasis and prevents the development of chronic disease [59]. Recent studies however introduce an alternative model in which resolution is not the end of immune responses to infection/injury, but that there is immunological activity occurring after the resolution cascade is complete that alters the immune physiology of the affected tissue post injury.

It has been demonstrated that even after the inciting stimulus has been removed and resolution processes have dampened pro-inflammatory signals and cleared the traditional innate type leukocytes, there is continued immunological activity occurring at the subclinical level. Using a model of resolving murine peritonitis induced by low-dose yeast cell extract, zymosan, or by bacterial infection with Streptococcus pneumoniae, elicited a hitherto overlooked second wave of leukocyte infiltration into the tissue that persisted for months [60]. Polychromatic flow cytometric analyses revealed these cells comprise distinct separate populations of innate immune cells including CD11b+/CD49+/CD115+/MHC-II+ myeloid derived suppressor cells (MDSCs), F-480 lo/MHC-II+/CD11c+ dendritic cells (DCs) and F4-80 int/CD11b macrophages [60]. Cells of lymphoid lineage were also found to appear in the tissue postresolution with natural killer (NK) cells peaking in number from days 9-14 and declining thereafter, a pattern similar was displayed by both CD4+ and CD8+ T cell populations [61]. These diverse populations were observed alongside expansion of the lymph nodes which were found to contain blood Ly6 $\mathrm{C}^{\text {hi }}$ monocyte derived dendritic cells as well as memory $\mathrm{T}$ and $\mathrm{B}$ lymphocytes from blood peritoneal origins.

These data showing immune activity post resolution are supported by a variety of studies. Da Fonseca et al. [62] observed that following clearance of Yersinia pseudotuberculosis infection in mice, innate immune cells, particularly DCs accumulated in the adipose tissue. Importantly, following resolution of the infection there were prolonged defects in the physical integrity of 
the gut-draining lymphatics, highlighted by leakage of the fluorescent long-chain fatty acid, Bodipy FL C16. This defect was sustained up to 10 months post-infection. Additionally, interruptions in the molecular and cellular interactions between the gut and mesenteric lymph nodes (MLN), led to impaired mucosal immune responses that persisted for 42 weeks in mice including reduced generation of regulatory T cells (Tregs), decreased Th17 induction and prolonged increased production of pro-inflammatory cytokines such as IL-1 $\beta$ and TNF $\alpha$ indicating a shift toward type-1 immunity [62]. Additionally, Collins et al. reported that infection with herpes simplex virus (HSV)-1 of mice leads to infiltration of CCR2-dependent cells in the skin peaking at day 7 post-infection, a time that coincides with viral clearance. Subsequently there were elevated numbers of DCs and macrophages locally, twofold and fourfold respectively, 30 days post-inflammation when compared with unaffected regions. The numerical increase in localised DC and macrophage populations was observed for at least 23 weeks post-infection, well after viral clearance, and enhanced interferon- $\gamma$ responses by virus-specific $\mathrm{CD}^{+} \mathrm{T}$ cells upon re-infection with HSV-1 thereby, protecting the tissue from reinfection [63]. Furthermore, when the irritant 1-fluoro-2,4-dinitrobenzene (DNFB) was applied to murine flank skin 30 days post HSV-1 infection, there were threefold more DCs and sixfold more macrophages compared with untreated skin. This highlights that the phenomenon of continued immune activity was not only confined to HSV-1 infection but is found more generally following an inflammatory response in the skin [63].

Previous studies also demonstrated that populations of immune cells have the potential to remain in tissues for months following resolution of acute inflammation. Yona et al. have shown that following resolution of thioglycolate induced peritonitis, monocyte derived cells persisted in the peritoneal cavity for more than 2 months after the acute infection. These were identified as $\mathrm{MHC} \mathrm{II}^{\mathrm{lo}} / \mathrm{F} 4-80^{\mathrm{hi}}$ macrophages, indicating an associated phenotypic switch and integration of monocyte - derived macrophages into the tissue resident macrophage pool [64]. 
Another study suggests that following a respiratory viral infection with mouse parainfluenza Sendai virus, gene expression microarray and real-time qPCR assay reveal a significant increase in the mRNA expression of intracellular and cell surface triggering receptor expressed on myeloid cells 2 (TREM2). TREM2 is expressed on the cell surface where it works in coordination with its adaptor protein DAP12 leading to the activation of PI3K, phospholipase $\mathrm{C}$ and Vav signalling pathways, promoting macrophage survival and preventing apoptosis [65]. Interestingly, the greatest increase in TREM2 expression did not occur during the acute infection, but long after clearance of infection, peaking at approximately 49 days. This is indicative of a role for TREM2 in facilitating macrophage accumulation in the lung after acute infection, thereby amplifying IL-13 production, and promoting the development of chronic lung disease [66]. Other studies, however, emphasise that recruited cellular persistence may be context specific. Using a vascular endothelial growth factor (VEGF) - based transgenic mouse model, in which VEGF expression is conditionally induced in an organ of choice, monocytes were recruited to the liver as part of a VEGF-initiated angiogenic programme. In this instance, monocyte persistence was short-lived with cells having only transiently populated the liver for up to 7 days before dying via apoptosis [67]. Thus, there is conflicting evidence of the longevity of macrophage and monocyte populations in tissues following immune resolution. However, it is important to appreciate that a diverse range of tissues may have different post-immune responses guided by their specific local microenvironment [59]. For instance, failure of monocyte persistence in the liver may be attributed to its highly regenerative phenotype which creates a unique immune microenvironment very different to that which is seen in the skin or peritoneal cavity. Further research is warranted to fully understand the dynamics of mononuclear phagocytes and the contexts which may allow for their long-term survival postresolution. 
Evidence of immune activity following resolution in humans has been investigated utilising a model of acute inflammation driven by intradermal UV killed E. coli in healthy male volunteers [68]. Similar to what has been reported in mouse models, there was evidence of sustained further cellular infiltration into the tissue following resolution. Flow cytometric analyses reveals an approximately tenfold increase of both CD4+/CD45RO+/CCR7- and CD8+/CD45RO+/CCR7- memory T cells. Histology also reveals a significant increase in the numbers of CD163+ macrophages at the site from day 7 up to at least 17 days post infection, these levels were significantly higher than that seen in naïve tissue [69]. Post-resolution conservation in both murine and human models adds credence to the emerging concept that resolution is not the end of immune-mediated response post-inflammation.

It is believed that immune activity post-resolution may be context dependent, supporting the view that the "beginning programmes the end" [70]. A parallel model, in which a high-dose of zymosan was injected into the peritoneum of mice was not associated with the cellular accumulation previously reported in the low-dose zymosan model [60]. There was no appearance of MDSCs or regulatory macrophages while Treg generation, lymph node expansion and lymphocyte repopulation were less pronounced [60]. The biological mechanisms behind how different degrees of inflammation may impact the post-resolution tissue need further investigation, however, based on these data we propose that a transient resolving inflammatory response has an unappreciated role in allowing for an environment conducive for controlling adaptive immune responses and maintaining tolerance. However, in the instance that there is an overexuberant inflammatory response, the resultant resolution process fails to impose this conducive environment. This hypothesis is supported by studies which show that mice with chronic exposure to TNF $\alpha$ had attenuated adaptive immune responses, with $\mathrm{T}$ cell responsiveness to previously encountered antigens being dampened [71]. 
This further supports the hypothesis that resolution facilitates interaction between the innate and adaptive arms of the immune system.

Collectively, these studies give confidence to the emerging concept that resolution is not the end of innate-mediated immune responses and that there is an abundance of immune activity occurring even after successful resolution.

\section{Post-resolution immune system remodelling}

This model in which there is a great deal of immunological activity occurring at the subclinical level post-resolution is hypothesised to instate changes to the cellular and biochemical makeup of affected tissues. Resolution, therefore, does not reinstate homeostasis, but rather leads to a state of 'adapted homeostasis' in which the tissue is innately different to the previous state.

Prostaglandin $\mathrm{E}_{2}\left(\mathrm{PGE}_{2}\right)$ is part of a large group of lipid mediators synthesised from membranederived arachidonic acid (AA) collectively termed prostanoids [72]. During inflammation there is rapid generation of pro-inflammatory $\mathrm{PGE}_{2}$. $\mathrm{PGE}_{2}$ synthesis is routinely targeted via cyclooxygenase (COX) enzymes, that break down AA to $\mathrm{PGE}_{2}$, using NSAIDs to dampen inflammation in chronic inflammatory diseases such as RA [73, 74]. However, is it now becoming clear that in addition to its pro-inflammatory role, $\mathrm{PGE}_{2}$ also exerts multiple modulatory and anti-inflammatory effects such as direct inhibition of $\mathrm{T}$ cell proliferation $[75$, 76] whilst driving MDSC formation [77-80]. Previous studies identified that mice deficient in the two COX enzymes, COX-1 (PTGS1) and COX-2 (PTGS2), or mice treated with COX inhibitors display exaggerated inflammatory responses in the lungs leading to the development of asthma [81]. Furthermore, $\mathrm{PGE}_{2}$ has been shown to prevent the development of allergic airway inflammation [82] and has been identified to have potent anti-inflammatory and antiasthmatic effects when signalling through the $\mathrm{PGE}_{2}$ receptor $3\left(\mathrm{EP}_{3}\right)$ [83]. Newson et al. utilised 
liquid chromatography - tandem mass spectrometry (LC-MS/MS) of cell free inflammatory exudates to reveal a prolonged period of $\mathrm{PGE}_{2}$ synthesis post-resolution, which effectively dampens aspects of innate and adaptive immunity triggering a phase of immune suppression [61]. The immunosuppressive activity of $\mathrm{PGE}_{2}$ largely depends on the production of cyclic adenosine monophosphate (cAMP) from adenosine triphosphate (ATP). Of the four $\mathrm{PGE}_{2}$ receptors, $\mathrm{PGE}_{2}$ receptor $2\left(\mathrm{EP}_{2}\right)$ and $4\left(\mathrm{EP}_{4}\right)$ ligation upregulates intracellular levels of cAMP which actively suppresses the production of pro-inflammatory cytokines from macrophages and DCs in an IL-10 dependent manner $[84,85]$. The importance of $\mathrm{EP}_{4}$ in resolution is demonstrated following murine infection with Streptococcus pneumoniae 21 days after lowdose zymosan. These mice became noticeably sicker, and had an increased bacterial load compared to naïve controls that received an equivalent dose of bacteria. Importantly, both inhibiting $\mathrm{PGE}_{2}$ synthesis or antagonising the $\mathrm{EP}_{4}$ receptor reversed these effects resulting in greater clearance of S. pneumoniae [61]. Collectively these studies allow us to re-evaluate the role of $\mathrm{PGE}_{2}$, previously thought of as singularly pro-inflammatory. We now appreciate the multifaceted functions $\mathrm{PGE}_{2}$ may play in immunity and in mediating 'adapted homeostasis'.

The role of lipid mediators during post-resolution is supported by a human model of acute inflammation (intradermal UV killed E. coli), in which increased synthesis of COX-derived prostanoids was apparent [69]. For example at 0hrs following infection $\mathrm{PGE}_{2}$ levels were $\sim 250 \mathrm{pg} / \mathrm{ml}$, by day 17 however, with successful resolution occurring by $72 \mathrm{hrs}, \mathrm{PGE}_{2}$ levels were $\sim 1400 \mathrm{pg} / \mathrm{ml}$, significantly higher than levels reported before the onset of inflammation [69]. Additionally, Zamuner et al. demonstrate a role for prostaglandin $\mathrm{D}_{2}\left(\mathrm{PGD}_{2}\right)$ following resolution of acute colitis in rats [86]. In this model of colitis induced by intracolonic administration of trinitrobenzenesulfonic acid, rats exhibited a significant increase more than threefold from approximately $1750 \mathrm{pg} / \mathrm{mg}$ to approximately $500 \mathrm{pg} / \mathrm{mg}$ in colonic $\mathrm{PGD}_{2}$ synthesis as well as elevated COX-2 and $\mathrm{PGD}_{2}$ synthase post resolution. This coincided with 
an $\sim 85 \%$ increase in the rate of colonic epithelial cell proliferation. It has previously been shown that colonic epithelium is markedly altered following the resolution of colitis in terms of its secretory function and its ability to function as a barrier to bacterial translocation long after the infection had resolved $[87,88]$. Importantly these alterations in post colitis increased susceptibility to the formation of neoplastic lesions after administration of the potent carcinogen azoxymethane (AOM). Interestingly, this risk was reversed upon selective COX-2 inhibition or with a $\mathrm{PGD}_{2}$ receptor (DP1) antagonist [86].

Alterations in immune homeostasis post-resolution do not only include biochemical changes, such as those reported in lipid mediator expression, but also changes in cellular phenotype and function. Didierlaurent et al. showed sustained desensitisation of alveolar macrophage toll-like receptors following the resolution of influenza infection, , which prevented further activation of inflammatory responses [89]. 4-6 weeks after resolution of influenza X31, mice were rechallenged with flagellin, a TLR5 ligand, and had significantly less neutrophil infiltration into the airways [89]. Furthermore, NF- $\mathrm{KB}$ nuclear localisation, measured as $\% \mathrm{p} 65$ translocation into the nucleus following $1 \mathrm{hr}$ stimulation with flagellin, decreases from $\sim 75 \%$ to $\sim 30 \%$ in mice after resolution of influenza infection, indicating the presence of prolonged desensitisation of TLR activation in alveolar macrophages [89]. Another adaption identified after resolution of acute inflammation is the upregulation of the receptor CD200R on alveolar macrophages which modulates cellular function via inhibiting its activation [90, 91]. Epithelial cells secrete soluble mediators such as IL-10, TGF $\beta$ and nitric oxide (NO) in response to binding of the immunoglobulin CD200 to CD200R, exerting strong inhibitory signals on surrounding cells expressing CD200R and thereby preventing their activation [90]. Furthermore, mice that lack CD200 develop severe inflammation following influenza infection [92]. These data collectively indicate that even after resolution of influenza infection there are pro-longed immune suppressive alterations to alveolar macrophages which desensitises their 
ability to respond to secondary infections. Although many studies have focused on elucidating phenotypical changes associated with alveolar macrophages in the lung, further studies are warranted to understand how inflammatory processes induce alterations in a tissue, stimulus and cellular specific manner.

Thus, it must be appreciated that the role of prostanoids in immunity stretches far beyond that of acute inflammation where it is implicated in driving heat, redness, swelling and pain but also in post-resolution where they display the capacity to induce long-term alterations in postresolution tissue environments. There is also increasing evidence of long-term alterations in cellular function following the resolution of inflammation which dictate innate immune responses to subsequent inflammatory stimuli. Further studies are needed to fully understand the post-resolution environment, it is clear however, that post-resolution tissues exhibit biochemical and cellular changes that bring about a new homeostasis or 'adapted homeostasis'.

\section{Post-resolution implications in chronic disease}

The origins of some of the most common chronic diseases including RA, IBD and many autoimmune diseases remain to be elucidated. Many factors have been implicated, including but not limited to; age, genetics and environment. Molecular hypotheses have put focus upon many possible causes such as molecular mimicry and bystander activation [93-95], along with innate immune dysfunction [6, 7] and failure to elicit adaptive immune responses [96, 97]. There is now emerging evidence that immune dysfunction leading to chronic disease can occur following the clearance of an infectious (bacterial or viral) stimuli $[62,98]$.

Da Fonseca et al. [62] proposed that a long-gone infection may set the stage for the development of chronic disease due to alterations is the immune system. They show that a 
single transient encounter with $Y$. pseudotuberculosis has profound effects on tissue specific immunity. The post-resolution environment in this case is characterised by lymphatic leakage in the mesenteric adipose tissue that redirected DCs to the adipose compartment thereby preventing their proper accumulation in the mesenteric lymph node. Chronic mesenteric lymphadenopathy is not limited to Yersinia infection, but is also evident in in a variety of other diseases including Crohn's disease and Coeliac disease $[99,100]$. The precise mechanism by which $Y$. pseudotuberculosis triggers these alterations to the lymphatic system is not understood, however, mucosal functions including tolerance and protective immunity are compromised. A key finding in this study is that $Y$. pseudotuberculosis infection may predispose to food allergy. Mice which displayed mesenteric lymphadenopathy induced by $Y$. pseudotuberculosis failed to acquire oral tolerance following oral ovalbumin (OVA) exposure and displayed a delayed type hypersensitivity reaction to OVA challenge. The breaking of tolerance in this case can be linked to a failure of migratory DCs to access the MLN. A dramatic decrease of DCs in the MLN, generation of Tregs and IgA, important for maintaining a tolerogenic environment, results in profound consequences for the normally tolerogenic mucosal environment. Thus, the authors propose that infections, despite effective resolution result in "immunological scarring", and that following a simple infection the complex balance between the immune system and the gastrointestinal microbiota is compromised creating a context for an otherwise innocuous microbe to become a chronic pathogen [62]. This connection between the immune system and the microbiome is frequently reported in the gastrointestinal tract which is home to the largest population of commensal organisms in the human body. It therefore maintains a unique immunoregulatory phenotype that prevents inappropriate immune activation to innocuous microbes. Upsetting this balance can create an environment favourable to chronic conditions. For example, the development inflammatory bowel disease (IBD) is associated with genes that are critical in maintenance of the epithelial 
barrier and regulation of innate and adaptive immune responses. In this instance, a failure of intestinal defence function and immunoregulatory function leads to sustained immune activation by commensal bacterial species such as members of the Enterobacteriaceae family $[101,102]$.

Da Fonseca's observations that acute infections may lead to chronic disease are supported by earlier evidence that in the murine lung, clearance of a viral infection still leads to chronic airway inflammation A single paramyxoviral infection in mice not only produced an episode of acute bronchiolitis, but also triggered airway hyperreactivity and goblet cell hyperplasia which lasted for at least one year after complete viral clearance [103]. Following complete clearance of Sendai virus- induced para-influenza, mice progressed to develop an asthma like disease, involving increased airway hyperreactivity, mucus production and eosinophilia. The cause of such asthma-like disease was mediated by sustained activity of NK T cells which drive macrophages to produce IL-13, a cytokine previously shown to mediate chronic allergic asthma disease $[104,105]$. Thus, even if the inciting stimulus is cleared, there is evidence of local immunological "mal-adaption", leading to a predisposition to chronic inflammation in the affected tissues.

Based on numerous studies, it is proposed that the resolution process is a critical step in maintaining tolerance to prevent the development of chronic disease, in particular autoimmunity. It has recently been elucidated that the sequence of events that follow resolution of acute inflammation, via low-dose zymosan peritoneal infection, results in a pro-longed period of immune suppressive $\mathrm{PGE}_{2}$ biosynthesis [61]. This creates an immune suppressive environment in which susceptibility to infection is established [60], while also impairing the host's ability to generate adaptive immune responses to antigens [61]. Therefore, it is proposed that the adapted homeostatic environment created by post-resolution is an evolutionary tradeoff, where the threat of secondary infection is a more desirable outcome than the development 
of immune activation in response to endogenous antigens, such as those generated during the resolution process via apoptotic cells. It transpires that this emerging concept is supported by further studies in which mice that experienced a high-dose zymosan challenge, with delayed resolution and the absence of a third post-resolution phase, displayed an accumulation of antibodies to double stranded (ds) DNA [61]. This occurrence was attributed to failure of adequate efferocytosis of apoptotic cells and lymphocytes, leading to build up of apoptotic bodies as in seen in SLE $[5,45]$, along with the absence of immune suppressive PGE $_{2}$, required to prevent further immune activation [61]. Chinen et al. have also demonstrated that the $\mathrm{PGE}_{2} /$ cyclic adenosine monophosphate (cAMP) system maintains tolerance to commensal bacteria in the intestine [106]. Collectively these studies indicate a role for $\mathrm{PGE}_{2}$ in preventing immune responses to harmless or endogenous antigens.

It is therefore proposed that the 'adapted homeostatic' environment is important for the maintenance of immune tolerance. However, evidence also suggests that the way in which inflammation resolves may dictate the post-resolution environment. As previously highlighted Newson et al. describe an alternative resolution pathway elicited by high-dose zymosan induced peritonitis in which there is overexuberant inflammation, a more severe response associated with systemic inflammation [61]. In this pathway, resolution no longer leads to postresolution and "adapted homeostasis", but instead results in the implementation of "maladapted homeostasis" an environment conducive to the development of chronic disease (fig. 1). Similarly, De Heer et al. demonstrated that in the absence of plasmacytoid DC (pDC) accumulation following exposure to ovalbumin (OVA) antigen and subsequent challenge three weeks later, mice developed cardinal features of asthma. These features include eosinophilic inflammation around bronchi and blood vessels, the occurrence of goblet cell hyperplasia, eosinophilia in the bronchoalveolar compartment, and the presence of OVA - specific immunoglobulin E (IgE) in the serum [107]. These observations in pDC - depleted mice were 
attributed to an increase in Th2 - type cytokine production which was actively suppressed by pDCs in wild type mice [107].

It is of clinical significance that the study of resolution, and the immune activity that occurs beyond it, might allow us to discover the origins of some chronic inflammatory diseases and autoimmune conditions. It also allows us to understand how infection can predispose individuals to the development of secondary infections, which are fast becoming untreatable due to the rise of antibiotic resistance.

\section{Concluding Remarks}

In the pursuit to discover treatments for chronic inflammatory and autoimmune diseases, the focus has primarily rested on targeting the onset of inflammation and the symptoms associated with it. Studies on inflammatory resolution have advanced our understanding of the processes and pathways that converge to terminate acute inflammatory responses, with the end outcome of avoiding potentially damaging chronic inflammation. Recent research highlights the benefits of targeting immune resolution processes, to actively promote resolution [8]. It is important therefore, that we understand all aspects of resolution processes to fully elucidate how they operate to understand how defects may lead to chronic inflammation. However, future research is needed to elucidate if targeting resolution pathways will be more effective that current therapies on the market.

Studies have challenged the dogma that tissues return to the physiological and biochemical state it existed in prior to an acute inflammatory response. We now believe there to a great deal of immunological activity occurring at a sub-clinical level, at the site of inflammation, which dictates the long-term physiological fate of tissues post-injury. Furthermore, a myriad of studies show that in the weeks, months and years after complete resolution, the tissue is predisposed to developing chronic inflammation indicating the presence of tissue immune 
alterations [62]. Thus, our understanding of inflammatory resolution is evolving although many questions remain unanswered (see Outstanding Questions). It remains to be elucidated what inflammatory stimuli will lead to continued immune activity following resolution or if postresolution is conserved across all inflammatory responses. Also, the importance of understanding the mechanisms, mediators and pathways that regulate alternate tissue environments is paramount.

Inflammatory resolution remains an exciting target for therapeutic intervention in chronic inflammation and autoimmunity. However, it is unlikely that one single therapeutic will be effective for all. It is becoming increasingly imperative to understand the specific resolution pathways involved in specific diseases to develop new and effective therapeutics. 


\section{References}

1. Takeuchi, O. and S. Akira, Pattern recognition receptors and inflammation. Cell, 2010. 140(6): p. 805-20.

2. Ala, A., A.P. Dhillon, and H.J. Hodgson, Role of cell adhesion molecules in leukocyte recruitment in the liver and gut. Int J Exp Pathol, 2003. 84(1): p. 1-16.

3. Kolaczkowska, E. and P. Kubes, Neutrophil recruitment and function in health and inflammation. Nature Reviews Immunology, 2013. 13(3): p. 159.

4. Smolen, J.S. and G. Steiner, Therapeutic strategies for rheumatoid arthritis. Nature Reviews Drug Discovery, 2003. 2(6): p. 473.

5. Shao, W.-H. and P.L. Cohen, Disturbances of apoptotic cell clearance in systemic lupus erythematosus. Arthritis research \& therapy, 2011. 13(1): p. 202.

6. Dinauer, M.C. and P. Newburger, The respiratory burst oxidase and the molecular genetics of chronic granulomatous disease. Critical reviews in clinical laboratory sciences, 1993. 30(4): p. 329-369.

7. Morgenstern, D.E., et al., Absence of respiratory burst in X-linked chronic granulomatous disease mice leads to abnormalities in both host defense and inflammatory response to Aspergillus fumigatus. Journal of Experimental Medicine, 1997. 185(2): p. 207-218.

8. Buckley, C.D., D.W. Gilroy, and C.N. Serhan, Proresolving lipid mediators and mechanisms in the resolution of acute inflammation. Immunity, 2014. 40(3): p. 315-327.

9. Buckley, C.D., et al., The resolution of inflammation. Nature Reviews Immunology, 2013. 13(1): p. 59.

10. Serhan, C.N., et al., Resolution of inflammation: state of the art, definitions and terms. The FASEB journal, 2007. 21(2): p. 325-332.

11. Winkelstein, J.A., et al., Chronic granulomatous disease. Report on a national registry of 368 patients. Medicine, 2000. 79(3): p. 155-169.

12. Armstrong, J. and P.A. Hart, Response of cultured macrophages to Mycobacterium tuberculosis, with observations on fusion of lysosomes with phagosomes. Journal of experimental medicine, 1971. 134(3): p. 713-740.

13. Sturgill-Koszycki, S., et al., Lack of acidification in Mycobacterium phagosomes produced by exclusion of the vesicular proton-ATPase. Science, 1994. 263(5147): p. 678-681.

14. Matsumura, T., et al., Identification of BCAP-L as a negative regulator of the TLR signalinginduced production of IL- 6 and IL-10 in macrophages by tyrosine phosphoproteomics. Biochemical and biophysical research communications, 2010. 400(2): p. 265-270.

15. Chandel, N.S., et al., Role of oxidants in NF-KB activation and TNF- $\alpha$ gene transcription induced by hypoxia and endotoxin. The Journal of Immunology, 2000. 165(2): p. 1013-1021.

16. Seymour, H., et al., Anti-TNF agents for rheumatoid arthritis. British journal of clinical pharmacology, 2001. 51(3): p. 201-208.

17. Akira, S. and K. Takeda, Toll-like receptor signalling. Nature reviews immunology, 2004. 4(7): p. 499.

18. Liu, J., et al., Identification and characterization of a unique leucine-rich repeat protein (LRRC33) that inhibits Toll-like receptor-mediated NF-KB activation. Biochemical and biophysical research communications, 2013. 434(1): p. 28-34.

19. Gilroy, D. and R. De Maeyer. New insights into the resolution of inflammation. in Seminars in immunology. 2015. Elsevier.

20. Perretti, M., et al., Mobilizing lipocortin 1 in adherent human leukocytes downregulates their transmigration. Nature medicine, 1996. 2(11): p. 1259-1262.

21. Ryan, G.B. and G. Majno, Acute inflammation. A review. The American journal of pathology, 1977. 86(1): p. 183.

22. Henson, P. and R. Johnston, Tissue injury in inflammation. Oxidants, proteinases, and cationic proteins. The Journal of clinical investigation, 1987. 79(3): p. 669-674. 
23. Weiss, S.J., Tissue destruction by neutrophils. New England Journal of Medicine, 1989. 320(6): p. 365-376.

24. Dean, R.A., et al., Macrophage-specific metalloelastase (MMP-12) truncates and inactivates $E L R+C X C$ chemokines and generates CCL2,-7,-8, and-13 antagonists: potential role of the macrophage in terminating polymorphonuclear leukocyte influx. Blood, 2008. 112(8): p. 34553464.

25. Charo, I.F. and R.M. Ransohoff, The many roles of chemokines and chemokine receptors in inflammation. New England Journal of Medicine, 2006. 354(6): p. 610-621.

26. Nibbs, R.J., et al., The B-chemokine receptor $D 6$ is expressed by lymphatic endothelium and a subset of vascular tumors. The American journal of pathology, 2001. 158(3): p. 867-877.

27. Di Liberto, D., et al., Role of the chemokine decoy receptor D6 in balancing inflammation, immune activation, and antimicrobial resistance in Mycobacterium tuberculosis infection. Journal of Experimental Medicine, 2008. 205(9): p. 2075-2084.

28. Murphy, P.M., et al., International union of pharmacology. XXII. Nomenclature for chemokine receptors. Pharmacological reviews, 2000. 52(1): p. 145-176.

29. Jamieson, T., et al., The chemokine receptor $D 6$ limits the inflammatory response in vivo. Nature immunology, 2005. 6(4): p. 403.

30. Henson, P.M., The final step in programmed cell death: phagocytes carry apoptotic cells to the grave. Essays in biochemistry, 2003. 39: p. 105-117.

31. Da Silva, F.P. and V. Nizet, Cell death during sepsis: integration of disintegration in the inflammatory response to overwhelming infection. Apoptosis, 2009. 14(4): p. 509-521.

32. Savill, J., Apoptosis in resolution of inflammation. Journal of leukocyte biology, 1997. 61(4): $p$. 375-380.

33. Lauber, K., et al., Clearance of apoptotic cells: getting rid of the corpses. Molecular cell, 2004. 14(3): p. 277-287.

34. Fadok, V.A., D.L. Bratton, and P.M. Henson, Phagocyte receptors for apoptotic cells: recognition, uptake, and consequences. The Journal of clinical investigation, 2001. 108(7): p. 957-962.

35. Mandal, D., et al., Fas-, caspase 8-, and caspase 3-dependent signaling regulates the activity of the aminophospholipid translocase and phosphatidylserine externalization in human erythrocytes. Journal of Biological Chemistry, 2005. 280(47): p. 39460-39467.

36. Bratton, D.L. and P.M. Henson, Apoptotic cell recognition: will the real phosphatidylserine receptor (s) please stand up? Current Biology, 2008. 18(2): p. R76-R79.

37. Miyanishi, M., et al., Identification of Tim4 as a phosphatidylserine receptor. Nature, 2007. 450(7168): p. 435.

38. Kobayashi, N., et al., TIM-1 and TIM-4 glycoproteins bind phosphatidylserine and mediate uptake of apoptotic cells. Immunity, 2007. 27(6): p. 927-940.

39. Kuchroo, V.K., et al., New roles for TIM family members in immune regulation. Nature Reviews Immunology, 2008. 8(8): p. 577.

40. Bystrom, J., et al., Resolution-phase macrophages possess a unique inflammatory phenotype that is controlled by cAMP. Blood, 2008. 112(10): p. 4117-4127.

41. Ariel, A. and C.N. Serhan, New lives given by cell death: macrophage differentiation following their encounter with apoptotic leukocytes during the resolution of inflammation. Frontiers in immunology, 2012. 3: p. 4.

42. Fadok, V.A., et al., Macrophages that have ingested apoptotic cells in vitro inhibit proinflammatory cytokine production through autocrine/paracrine mechanisms involving TGF-beta, PGE2, and PAF. The Journal of clinical investigation, 1998. 101(4): p. 890-898.

43. Schwab, J.M., et al., Resolvin E1 and protectin D1 activate inflammation-resolution programmes. Nature, 2007. 447(7146): p. 869.

44. Serhan, C.N., et al., Macrophage proresolving mediator maresin 1 stimulates tissue regeneration and controls pain. The FASEB Journal, 2012. 26(4): p. 1755-1765. 
45. Munoz, L.E., et al., Apoptosis in the pathogenesis of systemic lupus erythematosus. Lupus, 2008. 17(5): p. 371-375.

46. Grabiec, A.M. and T. Hussell, The role of airway macrophages in apoptotic cell clearance following acute and chronic lung inflammation. Semin Immunopathol, 2016. 38(4): p. 409-23.

47. Grabiec, A.M., et al., Diminished airway macrophage expression of the Axl receptor tyrosine kinase is associated with defective efferocytosis in asthma. J Allergy Clin Immunol, 2017. 140(4): p. 1144-1146.e4.

48. Firestein, G.S., M. Yeo, and N.J. Zvaifler, Apoptosis in rheumatoid arthritis synovium. The Journal of clinical investigation, 1995. 96(3): p. 1631-1638.

49. Ariel, A., et al., Apoptotic neutrophils and $T$ cells sequester chemokines during immune response resolution through modulation of CCR5 expression. Nat Immunol, 2006. 7(11): p. 1209-16.

50. Botto, M., et al., Homozygous C1q deficiency causes glomerulonephritis associated with multiple apoptotic bodies. Nature genetics, 1998. 19(1): p. 56.

51. Tager, A.M. and A.D. Luster, BLT1 and BLT2: the leukotriene B4 receptors. Prostaglandins, leukotrienes and essential fatty acids, 2003. 69(2-3): p. 123-134.

52. Crooks, S. and R. Stockley, Leukotriene B4. The international journal of biochemistry \& cell biology, 1998. 30(2): p. 173-178.

53. Cannetti, C.A., et al., IL-18 enhances collagen-induced arthritis by recruiting neutrophils via TNF- $\alpha$ and leukotriene B4. The Journal of Immunology, 2003. 171(2): p. 1009-1015.

54. Arita, M., et al., Resolvin E1 selectively interacts with leukotriene B4 receptor BLT1 and ChemR23 to regulate inflammation. The Journal of Immunology, 2007. 178(6): p. 3912-3917.

55. Krishnamoorthy, S., et al., Resolvin D1 binds human phagocytes with evidence for proresolving receptors. Proceedings of the National Academy of Sciences, 2010. 107(4): p. 1660-1665.

56. Fullerton, J.N. and D.W. Gilroy, Resolution of inflammation: a new therapeutic frontier. Nature reviews Drug discovery, 2016. 15(8): p. 551.

57. Arita, M., et al., Stereochemical assignment, antiinflammatory properties, and receptor for the omega-3 lipid mediator resolvin E1. Journal of Experimental Medicine, 2005. 201(5): p. 713722.

58. Ohira, T., et al., Resolvin E1 receptor activation signals phosphorylation and phagocytosis. Journal of Biological Chemistry, 2010. 285(5): p. 3451-3461.

59. Schett, G. and M.F. Neurath, Resolution of chronic inflammatory disease: universal and tissuespecific concepts. Nature communications, 2018. 9(1): p. 3261.

60. Newson, J., et al., Resolution of acute inflammation bridges the gap between innate and adaptive immunity. Blood, 2014. 124(11): p. 1748-64.

61. Newson, J., et al., Inflammatory Resolution Triggers a Prolonged Phase of Immune Suppression through COX-1/mPGES-1-Derived Prostaglandin E. Cell Rep, 2017. 20(13): p. 3162-3175.

62. da Fonseca, D.M., et al., Microbiota-dependent sequelae of acute infection compromise tissuespecific immunity. Cell, 2015. 163(2): p. 354-366.

63. Collins, N., et al., Sustained accumulation of antigen-presenting cells after infection promotes local T-cell immunity. Immunology and cell biology, 2017. 95(10): p. 878.

64. Yona, S., et al., Fate mapping reveals origins and dynamics of monocytes and tissue macrophages under homeostasis. Immunity, 2013. 38(1): p. 79-91.

65. Turnbull, I.R., et al., Cutting edge: TREM-2 attenuates macrophage activation. The Journal of Immunology, 2006. 177(6): p. 3520-3524.

66. Wu, K., et al., TREM-2 promotes macrophage survival and lung disease after respiratory viral infection. Journal of Experimental Medicine, 2015. 212(5): p. 681-697.

67. Avraham-Davidi, I., et al., On-site education of VEGF-recruited monocytes improves their performance as angiogenic and arteriogenic accessory cells. Journal of Experimental Medicine, 2013. 210(12): p. 2611-2625. 
68. Motwani, M.P., et al., Novel translational model of resolving inflammation triggered by UVkilled E. coli. The Journal of Pathology: Clinical Research, 2016. 2(3): p. 154-165.

69. Motwani, M.P., et al., Prolonged immune alteration following resolution of acute inflammation in humans. PLoS One, 2017. 12(10): p. e0186964.

70. Serhan, C.N. and J. Savill, Resolution of inflammation: the beginning programs the end. Nature immunology, 2005. 6(12): p. 1191.

71. Cope, A.P., et al., Chronic tumor necrosis factor alters $T$ cell responses by attenuating $T$ cell receptor signaling. Journal of Experimental Medicine, 1997. 185(9): p. 1573-1584.

72. Smith, W.L., Prostanoid biosynthesis and mechanisms of action. American Journal of Physiology-Renal Physiology, 1992. 263(2): p. F181-F191.

73. Vane, J.R., Inhibition of prostaglandin synthesis as a mechanism of action for aspirin-like drugs. Nature New Biology, 1971. 231(25): p. 232.

74. Silverstein, F.E., et al., Gastrointestinal toxicity with celecoxib vs nonsteroidal antiinflammatory drugs for osteoarthritis and rheumatoid arthritis: the CLASS study: a randomized controlled trial. Jama, 2000. 284(10): p. 1247-1255.

75. Baker, P.E., J.V. Fahey, and A. Munck, Prostaglandin inhibition of T-cell proliferation is mediated at two levels. Cellular immunology, 1981. 61(1): p. 52-61.

76. Betz, M. and B. Fox, Prostaglandin E2 inhibits production of Th1 lymphokines but not of Th2 lymphokines. The Journal of Immunology, 1991. 146(1): p. 108-113.

77. Mao, Y., et al., Inhibition of tumor-derived prostaglandin-e2 blocks the induction of myeloidderived suppressor cells and recovers natural killer cell activity. Clinical Cancer Research, 2014. 20(15): p. 4096-4106.

78. Obermajer, N. and P. Kalinski, Generation of myeloid-derived suppressor cells using prostaglandin E 2. Transplantation research, 2012. 1(1): p. 15.

79. Obermajer, N., et al., Positive feedback between PGE2 and COX2 redirects the differentiation of human dendritic cells towards stable myeloid-derived suppressor cells. Blood, 2011: p. blood-2011-07-365825.

80. Obermajer, N., et al., PGE2-dependent CXCL12 production and CXCR4 expression control the accumulation of human MDSCs in ovarian cancer environment. Cancer research, 2011: $p$. canres. 2449.2011.

81. Stokes Peebles Jr, R., et al., Selective cyclooxygenase-1 and-2 inhibitors each increase allergic inflammation and airway hyperresponsiveness in mice. American journal of respiratory and critical care medicine, 2002. 165(8): p. 1154-1160.

82. Lundequist, A., et al., Prostaglandin E2 exerts homeostatic regulation of pulmonary vascular remodeling in allergic airway inflammation. The Journal of Immunology, 2010. 184(1): p. 433441.

83. Kunikata, T., et al., Suppression of allergic inflammation by the prostaglandin E receptor subtype EP3. Nature immunology, 2005. 6(5): p. 524.

84. Shiraishi, H., et al., Prostaglandin E2 is a major soluble factor produced by stromal cells for preventing inflammatory cytokine production from dendritic cells. International immunology, 2008. 20(9): p. 1219-1229.

85. Koga, K., et al., Cyclic adenosine monophosphate suppresses the transcription of proinflammatory cytokines via the phosphorylated c-Fos protein. Immunity, 2009. 30(3): p. 372-383.

86. Zamuner, S.R., et al., Predisposition to colorectal cancer in rats with resolved colitis: role of cyclooxygenase-2-derived prostaglandin d2. The American journal of pathology, 2005. 167(5): p. $1293-1300$.

87. Bell, C.J., D.G. Gall, and J.L. Wallace, Disruption of colonic electrolyte transport in experimental colitis. American Journal of Physiology-Gastrointestinal and Liver Physiology, 1995. 268(4): p. G622-G630. 
88. Kachur, J., et al., Colitis reduces short-circuit current response to inflammatory mediators in rat colonic mucosa. Inflammation, 1995. 19(2): p. 245-259.

89. Didierlaurent, A., et al., Sustained desensitization to bacterial Toll-like receptor ligands after resolutionof respiratory influenza infection. Journal of Experimental Medicine, 2008. 205(2): p. 323-329.

90. Snelgrove, R.J., et al., A critical function for CD200 in lung immune homeostasis and the severity of influenza infection. Nature immunology, 2008. 9(9): p. 1074.

91. Kaur, M., et al., Macrophage adaptation in airway inflammatory resolution. Eur Respir Rev, 2015. 24(137): p. 510-5.

92. Goulding, J., et al., Lowering the threshold of lung innate immune cell activation alters susceptibility to secondary bacterial superinfection. Journal of Infectious Diseases, 2011. 204(7): p. 1086-1094.

93. Fujinami, R.S., et al., Molecular mimicry in virus infection: crossreaction of measles virus phosphoprotein or of herpes simplex virus protein with human intermediate filaments. Proceedings of the National Academy of Sciences, 1983. 80(8): p. 2346-2350.

94. Fujinami, R.S., et al., Molecular mimicry, bystander activation, or viral persistence: infections and autoimmune disease. Clinical microbiology reviews, 2006. 19(1): p. 80-94.

95. Woodland, D.L. and M.A. Blackman, Retroviral super-antigens and $T$ cells. International reviews of immunology, 1992. 8(4): p. 311-325.

96. Teijaro, J.R., et al., Persistent LCMV infection is controlled by blockade of type I interferon signaling. Science, 2013. 340(6129): p. 207-211.

97. Wilson, E. and D. Brooks, Blockade of chronic type I interferon signaling to control persistent virus infection (P6048). 2013, Am Assoc Immnol.

98. O'Connor, S.M., C.E. Taylor, and J.M. Hughes, Emerging infectious determinants of chronic diseases. Emerging infectious diseases, 2006. 12(7): p. 1051.

99. Lucey, B.C., J.W. Stuhlfaut, and J.A. Soto, Mesenteric lymph nodes seen at imaging: causes and significance. Radiographics, 2005. 25(2): p. 351-365.

100. Huppert, B.J., et al., Diagnosis of cavitating mesenteric lymph node syndrome in celiac disease using MRI. American Journal of Roentgenology, 2004. 183(5): p. 1375-1377.

101. Rivas, M.A., et al., Deep resequencing of GWAS loci identifies independent rare variants associated with inflammatory bowel disease. Nature genetics, 2011. 43(11): p. 1066.

102. Belkaid, Y. and T.W. Hand, Role of the microbiota in immunity and inflammation. Cell, 2014. 157(1): p. 121-141.

103. Walter, M.J., et al., Viral induction of a chronic asthma phenotype and genetic segregation from the acute response. The Journal of clinical investigation, 2002. 110(2): p. 165-175.

104. Crapster-Pregont, M., et al., Dendritic cells and alveolar macrophages mediate IL-13-induced airway inflammation and chemokine production. Journal of Allergy and Clinical Immunology, 2012. 129(6): p. 1621-1627. e3.

105. Kuperman, D.A., et al., Direct effects of interleukin-13 on epithelial cells cause airway hyperreactivity and mucus overproduction in asthma. Nature medicine, 2002. 8(8): p. 885.

106. Chinen, T., et al., Prostaglandin E2 and SOCS1 have a role in intestinal immune tolerance. Nature communications, 2011. 2: p. 190.

107. De Heer, H.J., et al., Essential role of lung plasmacytoid dendritic cells in preventing asthmatic reactions to harmless inhaled antigen. Journal of Experimental Medicine, 2004. 200(1): p. 8998.

108. Machado, F.S. and J. Aliberti, Role of lipoxin in the modulation of immune response during infection. International immunopharmacology, 2008. 8(10): p. 1316-1319.

109. Serhan, C.N., N. Chiang, and T.E. Van Dyke, Resolving inflammation: dual anti-inflammatory and pro-resolution lipid mediators. Nature Reviews Immunology, 2008. 8(5): p. 349.

110. Recchiuti, A., Resolvin D1 and its GPCRs in resolution circuits of inflammation. Prostaglandins \& other lipid mediators, 2013. 107: p. 64-76. 
111. Chiang, N., et al., Identification of resolvin D2 receptor mediating resolution of infections and organ protection. Journal of Experimental Medicine, 2015. 212(8): p. 1203-1217.

112. Serhan, C.N., et al., Maresins: novel macrophage mediators with potent antiinflammatory and proresolving actions. Journal of Experimental Medicine, 2009. 206(1): p. 15-23.

113. Gilroy, D.W., et al., Inducible cyclooxygenase may have anti-inflammatory properties. Nature medicine, 1999. 5(6): p. 698.

114. Rajakariar, R., et al., Hematopoietic prostaglandin D2 synthase controls the onset and resolution of acute inflammation through PGD2 and 15-deoxy 12-14 PGJ2. Proceedings of the National Academy of Sciences, 2007. 104(52): p. 20979-20984.

115. Pettipher, R. and T.T. Hansel, Antagonists of the prostaglandin D2 receptor CRTH2. Drug News Perspect, 2008. 21(6): p. 317-322.

116. Chen, L., F. Lv, and L. Pei, Annexin 1: A glucocorticoid-inducible protein that modulates inflammatory pain. European Journal of Pain, 2014. 18(3): p. 338-347.

117. Scannell, M., et al., Annexin-1 and peptide derivatives are released by apoptotic cells and stimulate phagocytosis of apoptotic neutrophils by macrophages. The Journal of Immunology, 2007. 178(7): p. 4595-4605.

118. Kourtzelis, I., et al., DEL-1 promotes macrophage efferocytosis and clearance of inflammation. Nature immunology, 2018: p. 1.

119. Lawrence, T. and C. Fong, The resolution of inflammation: anti-inflammatory roles for NF-KB. The international journal of biochemistry \& cell biology, 2010. 42(4): p. 519-523.

120. Ariel, A., et al., Apoptotic neutrophils and $T$ cells sequester chemokines during immune response resolution through modulation of CCR5 expression. Nature immunology, 2006. 7(11): p. 1209.

121. Fong, C.H.Y., et al., An antiinflammatory role for IKKB through the inhibition of "classical" macrophage activation. Journal of Experimental Medicine, 2008. 205(6): p. 1269-1276.

122. Sousa, L.P., et al., Cyclic AMP enhances resolution of allergic pleurisy by promoting inflammatory cell apoptosis via inhibition of PI3K/Akt and NF-KB. Biochemical pharmacology, 2009. 78(4): p. 396-405.

123. Rodrigues, D.H., et al., Absence of PI3KY leads to increased leukocyte apoptosis and diminished severity of experimental autoimmune encephalomyelitis. Journal of neuroimmunology, 2010. 222(1-2): p. 90-94.

124. Sousa, L.P., et al., PDE4 inhibition drives resolution of neutrophilic inflammation by inducing apoptosis in a PKA-PI3K/AKt-dependent and NF-KB-independent manner. Journal of leukocyte biology, 2010. 87(5): p. 895-904.

125. Sawatzky, D.A., et al., The involvement of the apoptosis-modulating proteins $E R K 1 / 2, B c l-x L$ and Bax in the resolution of acute inflammation in vivo. The American journal of pathology, 2006. 168(1): p. 33-41.

126. Rossi, A.G., et al., Regulation of macrophage phagocytosis of apoptotic cells by cAMP. The journal of immunology, 1998. 160(7): p. 3562-3568.

127. Divanovic, S., et al., Negative regulation of Toll-like receptor 4 signaling by the Toll-like receptor homolog RP105. Nature immunology, 2005. 6(6): p. 571.

128. Taganov, K.D., et al., NF-KB-dependent induction of microRNA miR-146, an inhibitor targeted to signaling proteins of innate immune responses. Proceedings of the National Academy of Sciences, 2006. 103(33): p. 12481-12486.

129. Sheedy, F.J., et al., Negative regulation of TLR4 via targeting of the proinflammatory tumor suppressor PDCD4 by the microRNA miR-21. Nature immunology, 2010. 11(2): p. 141.

130. Huber, A.R., et al., Regulation of transendothelial neutrophil migration by endogenous interleukin-8. Science, 1991. 254(5028): p. 99-102.

131. Paccaud, J.-P., J. Schifferli, and M. Baggiolini, NAP-1/L-8 induces up-regulation of CR1 receptors in human neutrophil leukocytes. Biochemical and biophysical research communications, 1990. 166(1): p. 187-192. 
132. Schenk, B.I., et al., Platelet-derived chemokines $C X C$ chemokine ligand ( $C X C L) 7$, connective tissue-activating peptide III, and CXCL4 differentially affect and cross-regulate neutrophil adhesion and transendothelial migration. The Journal of Immunology, 2002. 169(5): p. 26022610.

133. Farber, J.M., HuMig: a new human member of the chemokine family of cytokines. Biochemical and biophysical research communications, 1993. 192(1): p. 223-230.

134. Luster, A.D., J.C. Unkeless, and J.V. Ravetch, $y$-Interferon transcriptionally regulates an earlyresponse gene containing homology to platelet proteins. Nature, 1985. 315(6021): p. 672.

135. Jiang, Y., et al., Post-translational modification of a monocyte-specific chemoattractant synthesized by glioma, osteosarcoma, and vascular smooth muscle cells. Journal of Biological Chemistry, 1990. 265(30): p. 18318-18321.

136. Deshmane, S.L., et al., Monocyte chemoattractant protein-1 (MCP-1): an overview. Journal of interferon \& cytokine research, 2009. 29(6): p. 313-326.

137. Taguchi, M., et al., Patterns for RANTES secretion and intercellular adhesion molecule 1 expression mediate transepithelial $T$ cell traffic based on analyses in vitro and in vivo. Journal of Experimental Medicine, 1998. 187(12): p. 1927-1940.

138. Opdenakker, G., et al., Human monocyte chemotactic protein-3 (MCP-3): molecular cloning of the CDNA and comparison with other chemokines. Biochemical and biophysical research communications, 1993. 191(2): p. 535-542.

139. Van Damme, J., et al., Structural and functional identification of two human, tumor-derived monocyte chemotactic proteins (MCP-2 and MCP-3) belonging to the chemokine family. Journal of Experimental Medicine, 1992. 176(1): p. 59-65.

140. Garcia-Zepeda, E.A., et al., Human monocyte chemoattractant protein (MCP)-4 is a novel CC chemokine with activities on monocytes, eosinophils, and basophils induced in allergic and nonallergic inflammation that signals through the CC chemokine receptors (CCR)-2 and-3. The Journal of Immunology, 1996. 157(12): p. 5613-5626.

141. Uguccioni, M., et al., Monocyte chemotactic protein 4 (MCP-4), a novel structural and functional analogue of MCP-3 and eotaxin. Journal of Experimental Medicine, 1996. 183(5): $p$. 2379-2384.

142. Bazan, J.F., et al., A new class of membrane-bound chemokine with a CX3C motif. Nature, 1997. 385(6617): p. 640. 


\section{Figure Legend - The inflammatory response}

The acute inflammatory response is a complex but highly coordinated sequence of events. (1) Onset begins with the production of soluble mediators, including chemokines and cytokines, by resident cells such as tissue resident macrophages and dendritic cells at the site of infection/injury. Upregulation of cell adhesion molecules on circulating leukocytes and endothelial cells promote the influx of granulocytes from the blood which phagocytose and eliminate tissue debris and microorganisms through distinct intracellular mechanisms involving superoxide radicals, myeloperoxidase, proteases and lactoferrins, and extracellular mechanisms such as neutrophil extracellular traps. Onset makes way for the next phase of the inflammatory response, resolution, once the inciting stimulus has been cleared. (2) Once eliminated, resolution processes result in the termination of pro-inflammatory mediator synthesis and catabolise/sequester remaining mediators present in the tissue. This prevents further leukocyte recruitment and infiltration, leading to apoptosis of leukocytes and subsequent efferocytosis by tissue resident macrophages. (3) A new model in which resolution is not the end of immune responses to infection/injury adds a third phase after onset and resolution termed post-resolution. This new phase is characterised by an accumulation of immune cells in the tissue that persist even after successful resolution that bestow upon the tissue a state of "adapted homeostasis" that alters the immune physiology of post-inflamed tissues. Importantly, we believe that the development of "adapted homeostasis" is context dependent in which overexuberant inflammation or defective resolution may lead to "Maladapted homeostasis" and creation of an environment conducive to the development of chronic disease. 
Table 1. Mediators of Inflammatory Resolution

\begin{tabular}{|c|c|c|}
\hline Mediator or Effector & Receptor & Pro-resolution Functions \\
\hline \multicolumn{3}{|c|}{ Lipids } \\
\hline $\begin{array}{l}\text { Lipoxins } A_{4} \text { and } B_{4} \\
{[108,109]}\end{array}$ & $\begin{array}{l}\text { FPR2 and } \\
\text { GPR32 }\end{array}$ & $\begin{array}{l}\text { Inhibits granulocyte trafficking } \\
\text { Cytokine scavenging } \\
\text { Efferocytosis } \\
\text { Anti-inflammatory macrophage polarisation }\end{array}$ \\
\hline $\begin{array}{l}\text { Resolvin E1 } \\
{[54,58]}\end{array}$ & $\begin{array}{l}\text { BLT1 and } \\
\text { CMKLR1 }\end{array}$ & $\begin{array}{l}\text { Inhibits granulocyte trafficking } \\
\text { Dampens pro-inflammatory signalling } \\
\text { Efferocytosis } \\
\text { Anti-inflammatory macrophage polarisation }\end{array}$ \\
\hline $\begin{array}{l}\text { Resolvin D1 } \\
{[55,110]}\end{array}$ & $\begin{array}{l}\text { FPR2 and } \\
\text { GPR32 }\end{array}$ & $\begin{array}{l}\text { Inhibits granulocyte trafficking } \\
\text { Dampens pro-inflammatory signalling } \\
\text { Efferocytosis } \\
\text { Anti-inflammatory macrophage polarisation }\end{array}$ \\
\hline $\begin{array}{l}\text { Resolvin D2 } \\
{[111]}\end{array}$ & GPR18 & $\begin{array}{l}\text { Inhibits granulocyte trafficking } \\
\text { Efferocytosis }\end{array}$ \\
\hline $\begin{array}{l}\text { Maresins } \\
{[112]}\end{array}$ & & $\begin{array}{l}\text { Inhibits granulocyte trafficking } \\
\text { Efferocytosis }\end{array}$ \\
\hline $\begin{array}{l}\text { Protectin D1 } \\
{[43]}\end{array}$ & & $\begin{array}{l}\text { Inhibits granulocyte trafficking } \\
\text { Apoptosis }\end{array}$ \\
\hline $\begin{array}{l}\mathrm{PGD}_{2} \\
{[113-115]}\end{array}$ & DP1 and DP2 & Inhibits granulocyte trafficking \\
\hline $\begin{array}{l}15-\operatorname{deoxy} \Delta^{12-14}-\mathrm{PGJ}_{2} \\
{[113-115]}\end{array}$ & PPAR- $\gamma$ & $\begin{array}{l}\text { Inhibits granulocyte trafficking } \\
\text { Dampens pro-inflammatory signalling }\end{array}$ \\
\hline \multicolumn{3}{|c|}{ Proteins } \\
\hline $\begin{array}{l}\text { Annexin A1 } \\
{[116,117]}\end{array}$ & FPR2 & $\begin{array}{l}\text { Inhibits granulocyte trafficking } \\
\text { Efferocytosis } \\
\text { Anti-inflammatory macrophage polarisation }\end{array}$ \\
\hline $\begin{array}{l}\text { D6 } \\
{[27]}\end{array}$ & $\begin{array}{l}\text { Functions as a } \\
\text { scavenger } \\
\text { receptor }\end{array}$ & Cytokine scavenging \\
\hline $\begin{array}{l}\text { TIM-4 } \\
{[38]}\end{array}$ & PtdSer & Efferocytosis \\
\hline $\begin{array}{l}\text { DEL-1 } \\
{[118]}\end{array}$ & $\begin{array}{l}\alpha_{1} \beta_{2} \text { and } \alpha_{\mathrm{v}} \beta_{3} \\
\text { integrins, PtdSer }\end{array}$ & $\begin{array}{l}\text { Efferocytosis } \\
\text { Anti-inflammatory macrophage polarisation }\end{array}$ \\
\hline \multicolumn{3}{|c|}{ Changes in intracellular signalling pathways } \\
\hline $\begin{array}{l}\mathrm{NF}-\kappa \mathrm{B} \\
{[119-121]}\end{array}$ & & $\begin{array}{l}\text { Apoptosis } \\
\text { Anti-inflammatory macrophage polarisation }\end{array}$ \\
\hline $\begin{array}{l}\text { PI3K } \\
{[122-124]}\end{array}$ & & Apoptosis \\
\hline $\begin{array}{l}\text { ERK1 or ERK2 } \\
{[125]}\end{array}$ & & Apoptosis \\
\hline $\begin{array}{l}\text { cAMP } \\
{[122,126]}\end{array}$ & & $\begin{array}{l}\text { Apoptosis } \\
\text { Efferocytosis } \\
\text { Anti-inflammatory macrophage polarisation }\end{array}$ \\
\hline \multicolumn{3}{|c|}{ Intracellular regulators } \\
\hline
\end{tabular}




\begin{tabular}{|l|l|l|}
\hline $\begin{array}{l}\text { LRRC33 } \\
{[18]}\end{array}$ & Dampens pro-inflammatory signalling \\
\hline $\begin{array}{l}\text { RP105 } \\
{[127]}\end{array}$ & & \\
\hline $\begin{array}{l}\text { MicroRNAs (for } \\
\text { example, mIR-146 } \\
\text { and mIR-21) }\end{array}$ & & Destabilised pro-inflammatory mRNA \\
{$[128,129]$} & & \\
\hline
\end{tabular}

Adapted from Fullerton et al. [56]

Annexin A1 N-terminal derived peptide; BLT1, leukotriene $\mathrm{B}_{4}$ receptor; cAMP, cyclic AMP; DEL-1, developmental endothelial locus-1; D6, chemokine binding protein; ERK, extracellular-signal-related kinase; FPR, N-formyl peptide receptor; GPR, G-protein coupled receptor; LRRC33, leucine rich repeat-containing protein 33; ND, none defined, NF- $\kappa \mathrm{B}$, nuclear factor- $\kappa \mathrm{B} ; \mathrm{PGD}_{2}$, prostaglandin $\mathrm{D} 2 ; \mathrm{PGJ}_{2}$, prostaglandin $\mathrm{J} 2$; PI3K, phosphoinositide 3-kinase; PPAR $\gamma$, peroxisome proliferator-activated receptor- $\gamma$; TIM-4, T cell/transmembrane immunoglobulin mucin 
Table 2. Chemokines

\begin{tabular}{|c|c|c|c|c|}
\hline Chemokine & Family & Function & Receptor & References \\
\hline CXCL8 (IL-8) & $\begin{array}{l}\text { Alpha } \\
\text { Chemokines } \\
(\mathrm{CXC})\end{array}$ & $\begin{array}{l}\text { Chemoattractant for } \\
\text { neutrophils, basophils, and } \mathrm{T} \\
\text { cells }\end{array}$ & $\begin{array}{l}\text { CXCR1 } \\
\text { (IL- } \\
\text { 8RA), } \\
\text { CXCR2 } \\
\text { (IL-8RB), } \\
\text { DARC }\end{array}$ & {$[130,131]$} \\
\hline $\begin{array}{l}\text { CXCL7 (NAP- } \\
\text { 2) }\end{array}$ & $\begin{array}{l}\text { Alpha } \\
\text { Chemokines } \\
(\mathrm{CXC})\end{array}$ & $\begin{array}{l}\text { Potent chemoattractant and } \\
\text { activator of neutrophils. } \\
\text { Stimulates DNA synthesis, } \\
\text { mitosis, glycolysis, } \\
\text { intracellular CAMP } \\
\text { accumulation, } \text { PGE }_{2} \\
\text { secretion and synthesis of } \\
\text { hyaluronic acid. }\end{array}$ & $\begin{array}{l}\text { CXCR2 } \\
\text { (IL-8RB) }\end{array}$ & [132] \\
\hline CXCL9 (MIG) & $\begin{array}{l}\text { Alpha } \\
\text { Chemokines } \\
(\mathrm{CXC})\end{array}$ & $\begin{array}{l}\text { Produced by stimulated } \\
\text { monocytes, macrophages } \\
\text { and epithelial cells. } \\
\text { Selectively attracts Th1 } \\
\text { cells. }\end{array}$ & $\begin{array}{l}\text { CXCR3 } \\
\text { beta } \\
\text { isoform } \\
\text { (CD183b) }\end{array}$ & [133] \\
\hline $\begin{array}{l}\text { CXCL10 (IP- } \\
10)\end{array}$ & $\begin{array}{l}\text { Alpha } \\
\text { Chemokines } \\
(\mathrm{CXC})\end{array}$ & $\begin{array}{l}\text { Chemoattractant for CD4+ T } \\
\text { cells. Produced by a wide } \\
\text { variety of cells from } \\
\text { neutrophils to hepatocytes, } \\
\text { endothelial cells and } \\
\text { keratinocytes. }\end{array}$ & $\begin{array}{l}\text { CXCR3 } \\
\text { beta } \\
\text { isoform }\end{array}$ & [134] \\
\hline CCL2 (MCP-1) & $\begin{array}{l}\text { Beta } \\
\text { Chemokines } \\
(\mathrm{CC})\end{array}$ & $\begin{array}{l}\text { Chemoattractant for } \\
\text { monocytes and basophils. }\end{array}$ & CCR2 & {$[135,136]$} \\
\hline $\begin{array}{l}\text { CCL5 } \\
\text { (RANTES) }\end{array}$ & $\begin{array}{l}\text { Beta } \\
\text { Chemokines } \\
(\mathrm{CC})\end{array}$ & $\begin{array}{l}\text { Chemoattractant for } \\
\text { monocytes, memory } \mathrm{T} \\
\text { helper cells and eosinophils. }\end{array}$ & $\begin{array}{l}\text { CCR1, } \\
\text { CCR3, } \\
\text { CCR4, } \\
\text { CCR5, } \\
\text { DARC }\end{array}$ & [137] \\
\hline CCL7 (MCP-3) & $\begin{array}{l}\text { Beta } \\
\text { Chemokines } \\
(\mathrm{CC})\end{array}$ & $\begin{array}{l}\text { Attracts macrophages during } \\
\text { inflammation and } \\
\text { metastasis. In vivo substrate } \\
\text { of MMP2, an enzyme which } \\
\text { degrades components of the } \\
\text { extracellular matrix }\end{array}$ & $\begin{array}{l}\text { CCR1, } \\
\text { CCR2, } \\
\text { CCR3 }\end{array}$ & {$[138,139]$} \\
\hline CCL8 (MCP-2) & $\begin{array}{l}\text { Beta } \\
\text { Chemokines } \\
(\mathrm{CC})\end{array}$ & $\begin{array}{l}\text { Chemoattractant for } \\
\text { monocytes, lymphocytes, } \\
\text { basophils and eosinophils. }\end{array}$ & $\begin{array}{l}\text { CCR1, } \\
\text { CCR2, } \\
\text { CCR5, } \\
\text { CCR11 }\end{array}$ & [139] \\
\hline $\begin{array}{l}\text { CCL13 (MCP- } \\
\text { 4) }\end{array}$ & $\begin{array}{l}\text { Beta } \\
\text { Chemokines } \\
(\mathrm{CC})\end{array}$ & $\begin{array}{l}\text { Induces chemotaxis of } \\
\text { eosinophils, monocytes and } \\
\mathrm{T} \text { cells. }\end{array}$ & $\begin{array}{l}\text { CCR1. } \\
\text { CCR2, }\end{array}$ & {$[140,141]$} \\
\hline
\end{tabular}




\begin{tabular}{|l|l|l|l|l|}
\hline & & $\begin{array}{l}\text { CCR3, } \\
\text { CCR11 }\end{array}$ & \\
\hline $\begin{array}{l}\text { CXC } 3 \text { CL1 } \\
\text { (Fractalkine) }\end{array}$ & $\begin{array}{l}\text { Delta } \\
\text { Chemokines } \\
\text { (CX3C) }\end{array}$ & $\begin{array}{l}\text { Leukocyte chemoattractant } \\
\text { expressed in various tissues } \\
\text { including brain, heart, lung, } \\
\text { kidney, skeletal muscle and } \\
\text { testis. Upregulated in } \\
\text { endothelial cells and } \\
\text { microglia by inflammatory } \\
\text { signals. Its receptor mediates } \\
\text { both leukocyte migration } \\
\text { and adhesion. }\end{array}$ & [142] & \\
\hline
\end{tabular}




\section{Glossary}

Apoptotic bodies: Multiple vesicles formed by fragmentation of the cell during apoptosis.

Autoantibodies: Antibodies produced by the immune system that are directed against one or more of the individuals own proteins.

Cytokines: Proteins released by immune cells which mediate the function and behaviour neighbouring cells during steady state and inflammation.

Efferocytosis: The removal of effete, mainly apoptotic, cells by professional phagocytes, especially macrophages.

Matrix metalloproteinases (MMPs): A group of extracellular matrix proteins responsible for the degradation of proteins such as collagen during normal tissue turnover. They also participate in several other physiological processes such as bone remodelling, angiogenesis, immunity and wound healing.

Myeloid derived suppressor cells (MDSCs): Heterogenous group of immune cells of the myeloid lineage characterised by the immature state and ability the supress $\mathrm{T}$ cell responses.

Neutrophil extracellular traps (NETs): Large, extracellular, web-like structures composed of cytosolic and granule proteins that are assembled on a scaffold of decondensed chromatin. NETs released from neutrophils function to trap, neutralise and kill a variety of extracellular pathogens.

Prostanoids: A family of lipid mediators generated by the action of cyclooxygenase on a 20carbon unsaturated fatty acid, arachidonic acid which modulate cell function during inflammation and resolution. 
Specialised pro-resolving mediators (SPMs): Lipid mediators derived from the omega-3 essential fatty acids eicosapentaenoic acid (EPA) and docosahexaenoic acid (DHA) which can promote/accelerate inflammatory resolution.

Tissue homeostasis: A homeostatic process involved in the maintenance of an internal steady state within a defined tissue of an organism, including control of cellular proliferation and death and control of metabolic function.

Zymosan: A ligand found on the surface of fungi. It binds to Toll-like receptor 2 (TLR2) and dectin receptors. 


\section{Highlights Box}

- Uncontrolled inflammation is a key player in the pathogenesis of a myriad of chronic diseases including rheumatoid arthritis. Research has focused on understanding the mediators that cause chronic inflammatory responses in order to treat these diseases, predominantly aiming to inhibit the synthesis or action of mediators that drive inflammation using drugs such as non-steroidal anti-inflammatory drugs (NSAIDs)

- Specialised pro-resolving mediators (SPMs), identified in recent years, are endogenous mediators that include the n-3-derived families resolvins, protectins, and maresins, as well as arachidonic acid-derived (n-6) lipoxins, which play a key role in promoting resolution processes and are a key target for the development of therapeutics that promote resolution.

- Resolution is typically defined as a tightly regulated process that restores tissue homeostasis and prevents the development of chronic disease. Recent studies however introduce an alternative model in which resolution is not the end of immune responses to infection/injury, but that there is immunological activity occurring after the resolution cascade is complete that alters the immune physiology of the affected tissue post injury.

- "Adapted homeostasis" is an evolutionary trade-off, where the threat of secondary infection is a more desirable outcome than the development of immune activation in response to endogenous antigens.

- Understanding the events that occur during resolution and post-resolution to bring about adapted homeostasis may be key in discovering the origins of some chronic inflammatory and autoimmune diseases. 


\section{Outstanding Questions}

- Research has mostly focused on targeting the pathways that mediate the onset of inflammation. Will targeting resolution pathways be more effective than current therapies on the market?

- We believe the development of "adapted homeostasis" to be context dependent with the manner by which inflammation resolves dictating the events that occur post-resolution. What inflammatory stimuli will lead to the development and adapted homeostasis?

- Mediators previously identified to play key roles following resolution include lipid mediators and cytokines. What other mediators are present during post-resolution that are important in regulating the tissue environment?

- Is "adapted homeostasis" tissue specific? Will every tissue have their own unique adapted homeostatic environment or will adapted homeostasis pathways be conserved between different tissues? 


\section{Clinicians Corner}

- The cause of many chronic inflammatory and autoimmune diseases remains elusive with most therapies aimed at halting inflammation in its tracks.

- In recent years, an appreciation of targeting resolution processes is being recognised as an alternative to current treatments such as NSAIDs which are known to have immunosuppressive side effects.

- Defective resolution is implicated in a myriad of chronic diseases including; rheumatoid arthritis (RA), systemic erythematosus lupus (SLE), chronic obstructive pulmonary disease (COPD), atherosclerosis and glomerulonephritis.

- Our understanding of resolution is evolving, and we now appreciate that there is a great deal of immunological activity occurring at a sub-clinical level after resolution in tissues, which dictates immune responses to future inflammatory stimuli. 